\title{
Organisational processes around the investigation of serious events
}

\author{
Mark Cohen ${ }^{1}$
}

The Psychiatrist (2013), 37, 217-220, doi: 10.1192/pb.bp.113.042697

${ }^{1} \mathrm{NHS}$ Greater Glasgow and Clyde, Glasgow, UK

Correspondence to Mark Cohen (mark.cohen@ggc.scot.nhs.uk)

First received 10 Jan 2013, final revision $25 \mathrm{Apr} 2013$, accepted $29 \mathrm{Apr}$ 2013

\begin{abstract}
Summary This editorial focuses on a psychosocial application of psychoanalytic thinking to the processes which are in place to investigate serious events in psychiatric healthcare. It argues that the structures and processes in place can be understood with reference to organisational defences and to the 'actor-network theory'. A common reason for such an investigation is a completed suicide. It is suggested that defensive processes may occur in response to the anxieties associated with serious events such as suicide and are of concern in terms of psychiatric care retaining a capacity for emotionally involved practice.
\end{abstract}

Declaration of interest None.
This editorial examines the processes to investigate serious events in psychiatric services from an applied psychoanalytic perspective. The organisational means of investigating serious events can be understood - with reference to the actor-network theory - as a co-production of factors at personal, social and political levels. ${ }^{1}$ The importance of the causes and consequences at an individual level is examined with the possibility of an emotionally distanced and emptied form of functioning predominating. Also included are reflections on the relationship between psychoanalytic thinking and psychiatric care.

\section{Background and literature}

Iedema et $a l^{2}$ note the rising interest and awareness of iatrogenic injury and major public inquiries into wellpublicised events, for instance the Shipman Inquiry. They also comment on the development of methods to investigate incidents, such as root cause analysis (RCA) from the National Patient Safety Agency (www.nrls.npsa.nhs.uk/ resources/collections/root-cause-analysis). This is described as a 'systematic investigation technique that looks beyond the individuals concerned and seeks to understand the underlying causes and environmental context in which the incident happened'. Interviews with managers who are in receipt of RCA reports suggest that they will seek recommendations which are 'practical, sensible and achievable'. ${ }^{3}$ This may, however, be at the expense of the 'ambiguities, incommensurabilities and conflicting goals' ${ }^{3}$ which arise in the process of RCA.

In considering safety and iatrogenic injury, there has been significant interest in the model of system errors and a lessening of emphasis on the role of the individual. ${ }^{4}$ This encourages a process of examining the context in which individuals work (e.g. workload pressure, fatigue related to long working hours) as a factor which can contribute to accidents. Although in one sense welcome, it is also in keeping with a depersonalising tendency, in which the role or importance of the individual is diminished. There is in RCA some recognition that 'human factors' play a role in understanding incidents but this does not readily encompass the emotional world of staff and the relevance to psychiatric care.

Power $^{5-8}$ has expressed concern about the increasing tendency among organisations to seek the appearance of 'legitimacy' (I understand this term as referring to what is rightful and based on established or reasonable standards). He links this preoccupation to the wider rise of a consumerdriven culture and the decline of faith in government and its associated institutions. He suggests there is an attempt to achieve legitimacy by giving an overly dominant role to measurement, audit and 'the risk management of everything'? This has been associated with a reliance on quantifying, counting and monitoring, and a diminished value being placed on qualitative processes and professional opinions.

Power's analysis $^{7,8}$ suggests that senior members of an organisation will be faced with demands to demonstrate legitimacy. Perhaps associated with the 'legitimising' preoccupation, the volume of bureaucratic demands in mental healthcare has significantly increased in recent years. Contained within each of these developments is an aspiration for reflection and engagement with others, in a spirit of enquiry. However, there is a danger that the capacity of those within the system is overloaded by the increased work which is demanded, and there is a risk that staff meet these bureaucratic requirements by meeting the target but missing the point. ${ }^{9}$

In addition to these cultural and organisational influences, it is also helpful to consider some of the psychodynamic factors associated with suicide. Many authors comment on the hostility and destructiveness central to the suicidal act. ${ }^{10}$ Hale, ${ }^{11}$ in reviewing some of 
the fantasies held by those who attempt suicide, notes the frequency of a revenge fantasy, in which there is a wish for those surviving to be left with self-blaming and guilty feelings. In keeping with this, Heyno ${ }^{12}$ describes blaming and guilt in the context of organisational life and the sometimes resulting 'omnipotent fantasy' of prevention. This point is echoed by Briggs, ${ }^{13}$ who notes that attempting to achieve this fantasy may involve a preoccupying concern with audits, scrutiny and targets. This, in turn, touches on the work of Menzies-Lyth, ${ }^{14}$ in which ritualised practice is employed as a form of organisational defence from disturbing experience.

\section{Thinking about serious events}

The thinking in this editorial was initially prompted by the requirement to write an investigatory report on the organisational factors associated with the death of a patient by suicide. In the course of preparing this report I was struck by the depersonalised language and responses of the staff involved. This may have been influenced by many factors such as concerns about the investigatory process itself, as well as an emotional numbing in response to the suicide. ${ }^{14,15}$ However, I think that, in addition, the response was in keeping with a form of mental functioning which may be understood as being legitimate and approved of within mental health services. This does not preclude it being criticised, including by those who occupy senior positions in mental health services, but I would suggest that it is often the dominant and approved mindset within services and one which determines service organisation. The features of it are based on a determination to have clarity, particularly around boundaries. I think it is associated with an emotionally distanced approach. The focus may be on the clarity around the diagnosis of an individual or, in service terms, defining appropriate interventions associated with diagnostic categories. It may also be apparent in defining boundaries of responsibility, for individual patients and staff, and more generally for psychiatric services. It leaves little space for situations in which there is uncertainty or fluidity around the boundaries. In this mindset clear and definite divisions can be made. I think it can be associated with a way of viewing an individual and their internal states, meaning one experiences feeling either state $x$ or $y$. In addition, there are distinct and separate categories of people, and importantly, those people who are patients are clearly and distinctly separate to those people who are staff.

This functioning is promoted by being in touch with a state of 'everything all feels too much'. In this sense, it has adaptive qualities as it includes an attempt to get some distance from the problem in order to address it. It may be experienced as a state of feeling overwhelmed at somatic, emotional and intellectual levels, and may occur within individuals as well as between people and in organisations.

\section{Methods to investigate suicide}

The form of mental functioning described is particularly common when under significant pressure, as this is when it is likely that 'everything all feels too much'. Suicide and the associated precursors and sequelae are such events.

It is common in investigations following suicide that this form of mental functioning is reflected in the written reports which are produced. Personal relationships, including professional relationships with staff and more generally emotional factors do not emerge as factors in understanding these events. Case notes, in keeping with the dominance of this approach, do not usually contain an account of the relationship between staff and patients. However, in discussion about a suicide staff sometimes do talk about the difficulties in their relationship with the patient. In the investigatory processes this will rarely come to be regarded as a 'root cause' and therefore does not become identified as an area for organisational learning. This is in keeping with the underlying RCA method and the often prescribed format of the investigatory process. This promotes the 'practical, sensible and achievable', ${ }^{3}$ but perhaps constrains other contributions which might include 'ambiguities, incommensurabilities and conflicting goals' ${ }^{3}$ This may include consideration of the personal, subjective and emotional, and indeed from an RCA perspective such human characteristics are regarded as being implicitly unreliable. This form of thinking seems to push the writers of reports to be clear about boundaries, which reflects the approved form of clinical practice promoted within the organisation.

Reports also commonly come to be understood as answering a question about whether there had been any organisational failure of care. This is despite there being a strong argument that this question can be regarded as a separate issue to that of organisational learning and more in keeping with managing secondary reputational risk. ${ }^{7}$ Demonstrating legitimacy as a means of managing reputational risk can occur at all levels of an organisation, for example senior managers demonstrating to external monitoring agencies that they have a system to analyse serious events or, at another level, the writer of the report coming to clear and unambiguous conclusions. It is common for such reports to highlight issues proximal to the incident. The use of new policies, making mandatory the use of risk screening tools or reminders to staff of existing policies are frequent suggested remedies. The concern that staff get locked into 'closely coupled' solutions seems relevant when considering these approaches. ${ }^{16}$ This response, although understandable in terms of a wish to discharge responsibility, is questionable in terms of its effectiveness, ${ }^{17}$ and an increasing number of policies may inadvertently promote more fearful, defensive and depersonalised care.

\section{Formulating an understanding of the investigatory process}

The investigatory process can be considered with reference to Menzies-Lyth's ideas regarding a social structure which evolves as a means of offering a defence against anxieties. ${ }^{14}$ However, in this process the dynamic, personal and ongoing problem of achieving and maintaining a professional identity could be threatened and, crucially, there is a deleterious effect on patient care. In psychiatric healthcare 
the anxieties will include concerns about being taken over by irrational emotion and losing touch with objective reality. In addition to the 'every-day' difficulties for psychiatric services, serious incidents such as suicide generate strong feelings and defensive processes in staff. One organisational means of defence involves a split in which rationality becomes the preserve of legitimate staff, whereas subjective experience, emotions and distress become the experiences of patients. This in turn will influence the organisational structure and processes which are in place to investigate serious events.

The investigatory report process can also be viewed from the perspective of the actor-network theory (ANT), which suggests that complex social and material networks are established by the relationship between various human and non-human actors. One powerful factor is the concerns in the wider social and political community about mental ill health. Not uncommonly, this focuses on particular events such as homicides or suicides of patients who are involved in psychiatric services. In keeping with wider social and cultural changes, there is a requirement to demonstrate that services are 'fit for purpose'. This may be translated by managers of mental health services as a need to demonstrate legitimacy in the area of risk management. Importing a systemic approach developed in external industries is particularly welcome, as it is a response to the criticism of insularity and self-serving behaviour within the medical establishment. ${ }^{18}$ Psychiatrists concerned about the validity and scientific status of the profession ${ }^{19}$ may be more willing to unquestioningly adopt the same systems used in other more 'legitimate' - branches of medicine. This response will satisfy many critics who can then be recruited to join in a process of supporting this reflexive practice of medicine.

These factors converge and recruit each other into the formation of a relatively stable network, with the result that the system to investigate becomes an RCA-dominated investigatory process, meaning a complex network of factors is now captured by a single point. This 'black box' means that the complex system of various factors is unexamined and the solution of RCA is increasingly accepted, taken for granted and largely recognised as legitimate. ${ }^{20}$ The resultant network has a meaning and influence beyond the investigation of events. It is not merely a dry bureaucratic matter but has its own agency. It represents the official and approved functioning of the organisation and this power exerts a pressure for all working within it to comply with this process. In other terms, it serves to define and perpetuate a way of approaching clinical work. In this case it is a form of working which rightly places value on the rational, measurable and quantifiable but eschews the personal, subjective or emotional.

\section{Discussion}

The ideas in this editorial were generated in response to a request from a committee with a managerial responsibility to review and learn from critical incident reports. This asked that the writer take further the question about the role of relationships in understanding serious events. There has been much discussion about the difficult position and future direction of psychoanalysis and psychoanalytic psychotherapy within the National Health Service. An adaptive response from psychotherapists has involved the use of quantitative research methodologies in which definition and measurement are central. This has been successful not only in terms of devising therapeutic approaches to particular conditions, but also in addressing the long-standing criticism of there being a deficit of evidence for psychoanalytically based therapies. There is, though, a concern that in the uncontested dominance of this approach psychoanalytic thinking becomes limited to contributing to the treatment of defined conditions. This would diminish the way in which it might contribute to an understanding of whole situations, including organisational processes.

I wonder whether the request from the management committee to consider the relevance of relationships in understanding serious events involved a sense that something of the 'whole situation' was missing. Cooper \& Lousada ${ }^{21}$ suggest that to varying degrees and at different times, individuals and the wider organisation recognise the possibility of an emotional deadening as a phenomenon in staff working in highly emotionally demanding work. This may be associated with an experience of concern and guilt about the quality of work and linked to this a worry about contributing to something which can, at worst, be felt to be fraudulent.

I think this form of mental functioning may predominate in organisational settings when under significant emotional pressures. What then comes to the fore includes a rejection of a wish to know about emotional life. This is managed and perpetuated by adopting a detached and rational approach. This is an organisational defence which involves a split between business-minded rationality and subjective experience, emotions and distress. The difficulty is then to find space within the organisation from which there can be some reflection on this process.

In a similar vein, Cooper \& Lousada $^{21}$ speak of the need for containing spaces within organisations, to help process the feelings which are evoked in the course of the work. Without this, we, our patients and our future services lose out on the lively engagement which is necessary for development. There are accounts of this kind of work with clinical staff groups. ${ }^{22,23}$ However, in part this editorial is noting how different levels within an organisation may become disconnected, for instance the policy level might become detached from the emotional reality of clinical encounters. One possible implication of this is whether containing spaces within organisations may usefully include staff coming from policy levels within the organisation rather than being limited to clinical staff.

\section{About the author}

Mark Cohen is a consultant psychotherapist, NHS Greater Glasgow and Clyde, Dennistoun, Glasgow, UK.

\section{References}

1 Carter S, Davey Smith G. Health and security. In Security: Sociology and Social Worlds (eds S Carter, T Jordan, S Watson): 145-78. Manchester University Press, 2008. 
2 ledema RAM, Jorm C, Long L, Braithwaite J, Travaglia J, Westbrook M. Turning the medical gaze in upon itself: root cause analysis and the investigation of clinical error. Soc Sci Med 2006; 62: 1605-15.

3 ledema RAM, Jorm C, Braithwaite J. Managing the scope and impact of root cause analysis recommendations. J Health Organ Manag 2008; 22: 569-85.

4 Reason J. Human error: models and management. BMJ 2000; 320: 1-10.

5 Power M. The Audit Explosion. Demos, 1994.

6 Power $M$. The evolution of the audit society, its politics of control and the advent of CHI. In NICE, CHI and the NHS Reforms: Enabling Excellence of Imposing Control (UK Key Advances in Clinical Practice) (eds A Miles, JR Hampton, B Hurwitz): 127-38. Aesculapius Medical Press, 2000.

7 Power M. The Risk Management of Everything: Rethinking the Politics of Uncertainty. Demos, 2004.

8 Power M. Counting, control and calculation: reflections on measuring and management. Human Relations 2004; 57: 765-83.

9 Heath I, Hippisley-Cox J, Smeeth L. Measuring performance and missing the point? BMJ 2007; 335: 1075-6.

10 Briggs S, Crouch W, Lemma A. Introduction. In Relating to Self-Harm and Suicide: Psychoanalytic Perspectives on Practice, Theory and Prevention. Routledge, 2008.

11 Hale R. Psychoanalysis and suicide: process and typology. In Relating to Self-Harm and Suicide: Psychoanalytic Perspectives on Practice, Theory and Prevention (eds S Briggs, A Lemma, W Crouch): 13-24. Routledge, 2008.

12 Heyno A. On being affected without being infected: managing suicidal thoughts in student counselling. In Relating to Self-Harm and Suicide: Psychoanalytic Perspectives on Practice, Theory and Prevention (eds S Briggs, A Lemma, W Crouch): 175-86. Routledge, 2008.
13 Briggs S. Postvention: the impact of suicide and suicidal behaviours on family members, professionals and organisations. In Relating to SelfHarm and Suicide: Psychoanalytic Perspectives on Practice, Theory and Prevention (eds S Briggs, A Lemma, W Crouch): 224-37. Routledge, 2008.

14 Menzies-Lyth IEP. The Dynamics of the Social: Selected Essays, Volume 2. Free Association Books, 1989.

15 Magnana J. Attacks on life: suicidality and self-harm in young people. In Relating to Self-Harm and Suicide: Psychoanalytic Perspectives on Practice, Theory and Prevention (eds S Briggs, A Lemma, W Crouch): 109-27. Routledge, 2008.

16 ledema RAM, Jorm C, Braithwaite J, Travaglia J, Lum M. A root cause analysis of clinical error: confronting the disjunction between formal rules and situated clinical activity. Soc Sci Med 2006; 63: 1201-12.

17 Wu AW, Lipshutz AKB, Pronovost PG. Effectiveness and efficiency of root cause analysis in medicine. JAMA 2008; 299: 685-7.

18 Thompson AM, Stonebridge PA. Building a framework for trust: critical event analysis of deaths in surgical care. BMJ 2005; 330: 1139-42.

19 Craddock N, Antebi D, Attenburrow M-J, Bailey A, Carson A, Cowen P, et al. Wake-up call for British psychiatry. Br J Psychiatry 2008; 193: 6-9.

20 Latour B. Pandora's Hope: Essays on the Reality of Science Studies. Harvard University Press, 1999.

21 Cooper A, Lousada J. Borderline Welfare: Feeling and Fear of Feeling in Modern Welfare. Karnac Books, 2005.

22 Haigh R. Support systems. 2. Staff sensitivity groups. Adv Psychiatr Treat 2000; 6: 312-9.

23 Hess N. The function and value of staff groups on psychiatric wards Psychoanal Psychother 2001; 15: 121-30. 